\title{
ASSOCIATION OF SUBCLINICAL HYPOTHYROIDISM IN METABOLIC SYNDROME PATIENTS
}

\author{
JENNIFER S SUHASHINI, SAVITHA G*
}

Department of Biochemistry, Saveetha Dental College, Saveetha Institute of Medical and Technical Sciences, Saveetha University, Chennai, Tamil Nadu, India. Phone: +91-8946057653. Email: drsavitha80@gmail.com

Received: 17 April 2018, Revised and Accepted: 19 May 2018

ABSTRACT

Objectives: Subclinical hypothyroidism ( $\mathrm{SCH}$ ) is also the major risk for cardiovascular disease like metabolic syndrome (MetS). Hence, the aim of this study is to assess the association of SCH in MetS patients.

Materials and Methods: Ninety patients reporting to Saveetha Dental College and Hospitals were enrolled in the study which includes 40 patients with MetS and 40 healthy individuals. $5 \mathrm{ml}$ of venous blood was collected and centrifuged. Then, it is analyzed for fasting blood sugar, serum triglycerides, high-density lipoprotein cholesterol (HDL-c), low-density lipoprotein cholesterol (LDL-c), and very low-density lipoprotein (VLDL) using the standard kit method. Then, Free T3, Free T4, and thyroid-stimulating hormone (TSH) were estimated by ELISA method. The data obtained were subjected to statistical analysis using the SPSS software.

Results: SCH is $20 \%$ in cases when compared to $4.4 \%$ in controls, which was significant, p=0.024. The biochemical parameters were compared between the study population fasting blood glucose, triglycerides, total cholesterol, low-density lipoprotein cholesterol, and VLDL cholesterol was statistically significant, with $\mathrm{p}<0.001$. TSH levels showed significant difference between two groups with the $\mathrm{p}=0.002$.

Conclusion: MetS patients should be screened for the SCH as an important risk factor in evaluation protocol. Mere correction of TSH levels can reverse the associated morbidity in these patients rather than leaving them untreated pushing them to a state of overt hypothyroidism with its attendant complications.

Keywords: Metabolic syndrome, Sub-clinical hypothyroidism, Central adiposity, Hypertriglyceridemia, Impaired glucose tolerance.

(C) 2018 The Authors. Published by Innovare Academic Sciences Pvt Ltd. This is an open access article under the CC BY license (http://creativecommons. org/licenses/by/4. 0/) DOI: http://dx.doi.org/10.22159/ajpcr.2018.v11i9.26734

\section{INTRODUCTION}

Metabolic syndrome (MetS) affects major population in developed countries. It is a major risk for development of both type 2 diabetes mellitus, cardiovascular disease (CVD), and atherosclerosis. 20\% of Chennai urban population was affected by hypertension. Among these hypertensive patients, the prevalence of other components of MetS was diabetes in $31.8 \%$, impaired glucose tolerance in $17.9 \%$, hypercholesterolemia in $38.8 \%$, hypertriglyceridemia in $38 \%$, abdominal obesity in $64.3 \%$, and general obesity in $40 \%$ [1,2]. According to Jaipur Heart Watch Studies, the prevalence of MetS was 18.4\% in men, 30.9\% in women, and $24.9 \%$ overall in Indian population [3].

Kylin described the clustering of hyperuricemia, hyperinsulinemia, and hypertension [4]. In 1988, during the Seminal Banting Lecture, Reaven explained the central role of insulin resistance in syndrome $\mathrm{X}$, which has now become known as the MetS [5]. Obesity, insulin resistance, reduced physical activity, advanced age, and hormonal imbalance have been suggested as the underlying risk factors for the development of syndrome [6].

According to International Diabetes Federation, MetS patients have central adiposity (waist circumference $\geq 90 \mathrm{~cm}$ for men and $\geq 80 \mathrm{~cm}$ for women). Along with it, there are two or more of the other complications such as hypertriglyceridemia (fasting triglycerides $>150 \mathrm{mg} / \mathrm{dl}$ or on specific medication), high-density lipoprotein cholesterol (HDL-c), low-density lipoprotein cholesterol cholesterol (LDL-c) (HDL-c $<40 \mathrm{mg} / \mathrm{dl}$ and $<50 \mathrm{mg} / \mathrm{dl}$ for men and women, respectively, or on specific medication), hypertension (blood pressure $>130 \mathrm{~mm}$ systolic or $>85 \mathrm{~mm}$ diastolic or previous diagnosis or on specific medication), or hyperglycemia (fasting plasma glucose $\geq 100 \mathrm{mg} / \mathrm{dl}$ or previously diagnosed type 2 diabetes).
According to National Cholesterol Education Program and Adult Treatment Panel III (NCEP: ATP III), MetS patients have any of the three or more conditions such as central adiposity, hyperglycemia, hypertriglyceridemia, hypertension, and low HDL level [7]

Several studies have reported that higher thyroid-stimulating hormone (TSH) concentrations are associated with a higher likelihood for the occurrence of MetS, especially in females. In addition, thyroid disease, especially overt hypothyroidism, is associated with atherosclerotic CVD. Since MetS and thyroid dysfunction are independent risk factors of atherosclerotic CVD, the concurrent existence of the two will substantially increase the risk of CVD. Several studies have shown a significant association which links MetS with subclinical and overt hypothyroidism and the association seems to be more in females [8].

Studies consistently demonstrate thyroid hormone has multiple effects on the regulation of lipid synthesis, absorption, and metabolism. Elevated levels of serum total cholesterol, low-density lipoprotein cholesterol (LDL-C), apolipoprotein B, lipoprotein a, and possibly triglycerides in individuals with overt hypothyroidism, all of which are reversible with levothyroxine therapy. It is estimated that $1-11 \%$ of all patients with dyslipidemia have subclinical hypothyroidism (SCH). SCH is mild thyroid disorder if left untreated leads to overt hypothyroidism in many cases [9].

SCH is defined as an asymptomatic condition with serum thyroidstimulating hormone (TSH) level above the upper limit of normal despite normal levels of serum free thyroxine. SCH or mild thyroid failure is a common problem, with a prevalence of $3 \%-8 \%$ in the population without known thyroid disease. The prevalence increases with age and is higher in women than men. Antithyroid antibodies can be detected in $80 \%$ of patients with $\mathrm{SCH}$, and $80 \%$ of patients with $\mathrm{SCH}$ 


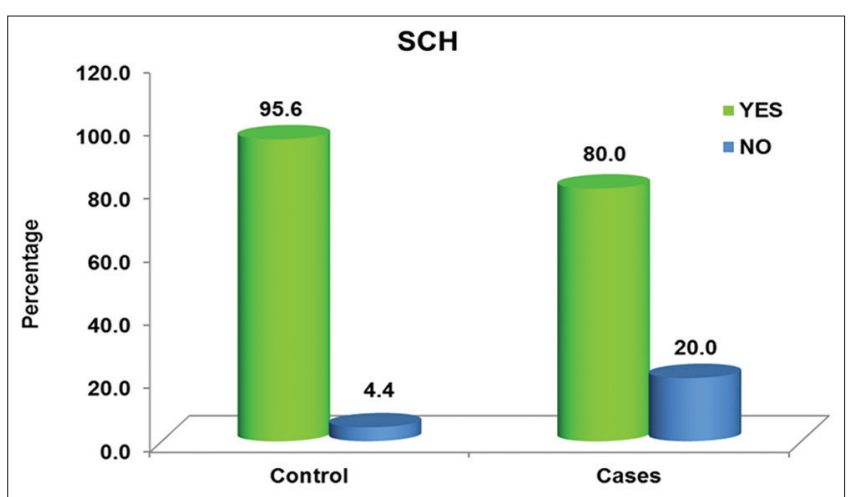

Fig. 1: Comparison of subclinical hypothyroidism in between cases and controls

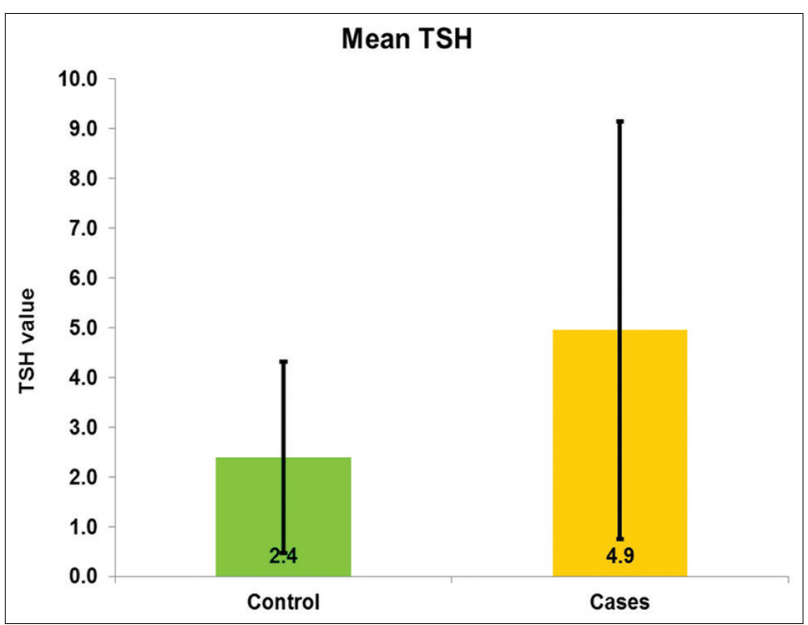

Fig. 2: Comparison of $\mathrm{FT}_{3}, \mathrm{FT}_{4}$, and thyroid-stimulating hormone between two groups

Table 1: Comparison of SCH in between cases and controls

\begin{tabular}{|c|c|c|c|c|c|}
\hline \multirow[t]{2}{*}{ SCH } & \multicolumn{2}{|l|}{ Group } & \multirow[t]{2}{*}{ Total } & \multirow[t]{3}{*}{$\chi^{2}$ Value } & \multirow[t]{3}{*}{ p value } \\
\hline & Control & Cases & & & \\
\hline & n (\%) & n (\%) & n (\%) & & \\
\hline No & $43(95.6)$ & $36(80.0)$ & 79 (87.8) & 5.075 & 0.024 \\
\hline Yes & $2(4.4)$ & $9(20.0)$ & $11(12.2)$ & & \\
\hline Total & $45(100.0)$ & $45(100.0)$ & $90(100.0)$ & & \\
\hline
\end{tabular}

SCH: Subclinical hypothyroidism

have a serum TSH of $<10 \mathrm{mIU} / \mathrm{L}$. There is growing evidence that $\mathrm{SCH}$ is associated with lipid abnormalities, increasing cardiovascular risk, and metabolic disorders such as hyperlipidemia, hypertension, low-grade inflammation, and hypercoagulability particularly in older women [10].

SCH and MetS have common manifestations and finding the association between the two can reduce the burden not only CVD but also the associated conditions such as diabetes mellitus, obesity, and dyslipidemia. This can in turn reduce the economic burden not only to the individual but also to the society and also enhance one's quality of life.

As patients suffering from MetS and SCH have a compounded risk for the development of CVD, establishing an association between the two has widespread clinical implications.

\section{MATERIALS AND METHODS}

Patients were selected from those attending the outpatient Department of Saveetha Dental College and Hospitals and divided into two groups as follows:

Group I - Normal healthy individuals - 45 individuals.

Group II - Patients with MetS - 45 individuals.

\section{Inclusion criteria}

Individuals with the age group of 35-55 years were included in the study. Patients with confirmed diagnosis of MetS based on history and blood pressure measurement using sphygmomanometer, lipid profile estimation, and NCEP criteria for MetS.

\section{Exclusion criteria}

- Known endocrine disorder,

Taking medications for altered thyroid functions or lipid levels

- Pregnant women

- Patients with abdominal mass/Ascites/liver disease, heart disease, and renal disorder.

\section{Sample collection}

Informed consent was obtained from the patient before sample collection. $5 \mathrm{ml}$ of venous blood was collected and distributed in plain collection tubes and centrifuged in $3000 \mathrm{rpm}$ for serum. Then, serum was separated and then it is analyzed for fasting blood sugar (FBS) by GOD-POD method, serum cholesterol by cholesterol esterase-oxidase method, serum triglycerides by colorimetric enzymatic method, HDL-c by phosphotungstic acid method, LDL-c, and very low-density lipoprotein cholesterol (VLDL-c) were calculated by Friedewald's formula. Serum Free T3, Free T4, and TSH levels were estimated by ELISA method.

\section{RESULTS}

All the data were analyzed using SPSS package. Student t-test analysis was done to find out significant differences between the two groups. All the tests were considered significant at $\mathrm{p}<0.05$ level.

Subclinical hypothyroidism is $20 \%$ in cases when compared to $4.4 \%$ in controls, which was significant, $p=0.024$.(Table1, Fig 1)

When the biochemical parameters were compared between the study population Fasting blood glucose, Triglycerides, Total cholesterol, low dense lipoprotein cholesterol, and very low density lipoprotein cholesterol were statistically significant, with p value $<0.001$. (Table 2 )

HDL-c was not statistically significant.

Comparison of FT3 and FT4 levels between cases and controls were not significant. But TSH levels showed significance with the $p$ value of 0.002.(Table 3, Fig 2)

\section{DISCUSSION}

The study conducted in 45 MetS patients and 45 healthy controls to look for an association between $\mathrm{SCH}$ in MetS patients and healthy controls revealed a strong association of SCH in MetS patients with the $\mathrm{p}=0.024$.

The lipid parameters which were also statistically significant between study groups except HDL-c, with mean values being high in cases when compared to the controls confirms that MetS patients have dyslipidemia in comparison to controls.

The central adiposity in MetS patients which predisposes them to insulin resistance causes an activation of hormone-sensitive lipase and inactivation of lipoprotein lipase leading to lipolysis and elevation of VLDL levels. Furthermore, insulin resistance impairs the activity of 
Table 2: Comparison of biochemical parameters in between two groups

\begin{tabular}{|c|c|c|c|c|c|}
\hline Parameters & Group & $\mathbf{N}$ & Mean \pm SD & t-Value & $\mathbf{p}$ \\
\hline \multirow[t]{2}{*}{ FBS } & Control & 45 & $84.56 \pm 11.802$ & 4.220 & $<0.001$ \\
\hline & Cases & 45 & $105.56 \pm 31.222$ & & \\
\hline \multirow[t]{2}{*}{ TGL } & Control & 45 & $102.76 \pm 50.453$ & 12.017 & $<0.001$ \\
\hline & Cases & 45 & $227.47 \pm 47.971$ & & \\
\hline \multirow[t]{2}{*}{ T.Chol } & Control & 45 & $160.58 \pm 28.391$ & 6.241 & $<0.001$ \\
\hline & Cases & 45 & $195.02 \pm 23.762$ & & \\
\hline HDL & Control & 45 & $37.44 \pm 8.024$ & 1.527 & 0.131 \\
\hline \multirow[t]{2}{*}{ LDL } & Control & 45 & $102.80 \pm 26.886$ & 2.122 & 0.037 \\
\hline & Cases & 45 & $113.69 \pm 21.506$ & & \\
\hline \multirow{2}{*}{ VLDL } & Control & 45 & $20.53 \pm 10.069$ & 12.037 & $<0.001$ \\
\hline & Cases & 45 & $45.51 \pm 9.612$ & & \\
\hline
\end{tabular}

Table 3: Comparison of FT3, FT4, and TSH between two groups

\begin{tabular}{|c|c|c|c|c|c|}
\hline \multirow[t]{3}{*}{ FT3 } & \multicolumn{2}{|l|}{ Group } & \multirow{3}{*}{$\begin{array}{l}\text { Total } \\
\text { n (\%) }\end{array}$} & \multirow[t]{3}{*}{$\chi^{2}$ value } & \multirow[t]{3}{*}{$p$ value } \\
\hline & \multirow{2}{*}{$\begin{array}{l}\text { Control } \\
\mathbf{n}(\%)\end{array}$} & \multirow{2}{*}{$\begin{array}{l}\text { Cases } \\
\text { n (\%) }\end{array}$} & & & \\
\hline & & & & & \\
\hline Normal & $41(91.1)$ & $43(95.6)$ & $84(93.3)$ & 0.714 & 0.338 \\
\hline Abnormal & $4(8.9)$ & $2(4.4)$ & $6(6.7)$ & & \\
\hline Total & $45(100.0)$ & $45(100.0)$ & $90(100.0)$ & & \\
\hline \multicolumn{6}{|l|}{ FT4 } \\
\hline Normal & 39 (86.7) & $42(93.3)$ & $81(90.0)$ & 1.111 & 0.242 \\
\hline Abnormal & $6(13.3)$ & $3(6.7)$ & $9(10.0)$ & & \\
\hline Total & $45(100.0)$ & $45(100.0)$ & $90(100.0)$ & & \\
\hline \multirow[t]{3}{*}{ TSH } & Group & $\mathbf{N}$ & Mean \pm SD & $\mathbf{t}$ & $\mathbf{p}$ \\
\hline & Control & 45 & $2.39131 \pm 1.925020$ & 3.206 & 0.002 \\
\hline & Cases & 45 & $4.94844 \pm 4.991676$ & & \\
\hline
\end{tabular}

TSH: Thyroid-stimulating hormone, SD: Standard deviation

cholesterol ester transfer protein, thereby altering the morphology of LDL-c and HDL-c leading to elevated LDL-c and decreased HDL-c [11].

FBS value is significant between the study groups, $\mathrm{p}<0.001$. MetS patients have high glucose levels as compared to controls indicating underlying insulin resistance in these patients which causes the elevation of glucose levels [12].

The incidence of SCH in cases is $20 \%$ as compared to $4.4 \%$ in controls which is statistically significant. This fact throws light on pathogenesis of MetS in which SCH plays a predominant role.

It has been recognized that TSH receptors are also located in the preadipocytes and adipocytes in addition to brain, testes, kidney, heart, bone, thymus, lymphocytes, and fibroblasts [13].

$\mathrm{SCH}$, a condition in which T3, T4 levels, is being maintained normal at the expense of an increased TSH levels contributes to the development of MetS. Elevated TSH which binds to its receptors of pre-adipocytes is responsible for the preferential differentiation of pre-adipocytes into adipocytes causing an expansion of adipose tissue mass [13-15]. This expanded adipose tissue is the culprit behind the manifestations of MetS.

The expanded adipose tissue increases the adipokines secretion. Hence, leptin, tumor necrosis factor $\alpha$, and interleukin-6 [16] levels are increased. However, adiponectin secretion is reduced which is the only protective adipokine secreted by the adipocytes. The elevated adipokines cause chronic inflammatory response and insulin resistance $[17,18]$.

The effect of the TSH on adipocytes was in it causes lipolysis which increases the free fatty acid concentrations in plasma is responsible for causing insulin resistance [19].
Hence, MetS patients should be screened for the SCH as an important risk factor in evaluation protocol. Mere correction of TSH levels can reverse the associated morbidity in these patients rather than leaving them untreated pushing them to a state of overt hypothyroidism with its attendant complications.

\section{CONCLUSION}

Association of SCH in MetS patients as compared to healthy controls is substantial in this case-control study which revealed a statistical significance of $\mathrm{p}=0.024$. Several studies are in progression to document the beneficial effects of correction of SCH in MetS patients reducing the associated morbidity and progression to overt hypothyroidism in MetS patients.

\section{AUTHOR'S CONTRIBUTIONS}

Concept and study design were done by Dr. G. Savitha. Data acquisition was done by Miss. Jennifer S Subashini. Data interpretation, statistical analysis, manuscript drafting, and review were done by all authors. All authors took part in the conduction of the study.

\section{CONFLICT OF INTEREST}

The authors of this article declare no conflict of interest in this study.

\section{FINANCIAL SUPPORT AND SPONSORSHIP}

Nil.

\section{REFERENCES}

1. Shantha GP, KumarAA, Jeyachandran V, Rajamanickam D, Rajkumar K, Salim S, et al. Association between primary hypothyroidism and metabolic syndrome and the role of $\mathrm{C}$ reactive protein: A cross-sectional study from south India. Thyroid Res 2009;2:2. 
2. Mohan V, Deepa M, Farooq S, Datta M, Deepa R. Prevalence, awareness and control of hypertension in Chennai - The Chennai urban rural epidemiology study (CURES-52). J Assoc Physicians India 2007;55:326-32.

3. Gupta R, Deedwania PC, Gupta A, Rastogi S, Panwar RB, Kothari K. Prevalence of metabolic syndrome in an Indian urban population. Int $\mathrm{J}$ Cardiol 2004;97:257-61.

4. Kylin E. Studies of the hypertension-hyperglycemia-hyperuricemia syndrome (German). Zentralbl Inn Med 1923;44:105-27.

5. Reaven GM. Banting lecture 1988. Role of insulin resistance in human disease. Diabetes 1988;37 Suppl 12:1595-607.

6. Nerkar D, Mukherjee A, Mehta BM, Banerjee S. Metabolic syndrome associated complications. Int J Pharm Pharm Sci 2015;7 Supp1 7:22-5.

7. Guru EP, Savitha G. Prevalence of coronary atherosclerotic heart disease in metabolic syndrome patients. J Pharm Sci Res 2015;7 Suppl 9:724-6.

8. Agarwal G, Sudhakar MK, Singh M, Senthil N, Sajendran AR. The prevalence of thyroid dysfunction among South Indian women with metabolic syndrome. J Clin Diag Res 2012;5:213-6.

9. Pearce EN. Update in lipid alterations in subclinical hypothyroidism. J Clin Endocrinol Metab 2012;97 Suppl 2:326-33.

10. Fatourechi V. Subclinical hypothyroidism: An update for primary care physicians. Mayo Clin Proc 2009;84 Suppl 1:65-71.

11. Lewis GF, Carpentier A, Adeli K, Giacca A. Disordered fat storage and mobilization in the pathogenesis of insulin resistance and type 2 diabetes. Endocr Rev 2002;23:201-29.

12. Lam TK, Carpentier A, Lewis GF, van de Werve G, Fantus IG,
Giacca A, et al. Mechanisms of the free fatty acid-induced increase in hepatic glucose production. Am J Physiol Endocrinol Metab 2003;284:E863-73.

13. de Lloyd A, Bursell J, Gregory JW, Rees DA, Ludgate M. TSH receptor activation and body composition. J Endocrinol 2010;204:13-20.

14. de Moura Souza A, Sichieri R. Association between serum TSH concentration within the normal range and adiposity. Eur J Endocrinol 2011;165:11-5

15. Tehrani FR, Tohidi M, Dovom MR, Azizi F. A population based study on the association of thyroid status with components of the metabolic syndrome. J Diabetes Metab 2011;2 Suppl 8:156.

16. Antunes TT, Gagnon AM, Bell A, Sorisky A. Thyroid-stimulating hormone stimulates interleukin-6 release from 3T3-L1 adipocytes through a cAMP-protein kinase A pathway. Obesity Res 2005;13 Suppl 12:2066-71.

17. Al-Biati HA, Sahib AS, Ismail SH. Effects of metformin and glibenclamide combination in Iraqi obese patients with metabolic syndrome. Int J Pharm Pharm Sci 2014;6 Suppl 10:501-3.

18. Lai Y, Wang J, Jiang F, Wang B, Chen Y, Li M, et al. The relationship between serum thyrotropin and components of metabolic syndrome. Endocr J 2011;58:23-30.

19. Gagnon A, Antunes TT, Ly T, Pongsuwan P, Gavin C, Lochnan HA, et al. Thyroid-stimulating hormone stimulates lipolysis in adipocytes in culture and raises serum free fatty acid levels in vivo. Metabolism 2010;59:547-53. 